\title{
The Sperm Specific Protein Proakap4 as an Innovative Marker to Evaluate Sperm Quality and Fertility
}

\author{
Nicolas Sergeant ${ }^{1,2}$, Lamia Briand-Amirat ${ }^{3}$, Djemil Bencharif ${ }^{3}$ and Maryse Delehedde M $^{2 *}$ \\ ${ }^{1}$ University of Lille, France
}

${ }^{2} S P Q I, 4 B i o D x-B r e e d i n g ~ S e c t i o n$, France

${ }^{3}$ Oniris, Nantes-Atlantic College of Veterinary Medicine, France

Submission: March 18, 2019; Published: March 25, 2019

*Corresponding author: Maryse Delehedde, SPQI-4BioDx, 1 place de Verdun, 59045 Lille, France

\begin{abstract}
As classical methods for semen analyses (i.e. motility, concentration, morphology, etc.) remains unsatisfactory in determining fertility outcomes in livestock animals, new methods based on proteomic markers have been recently introduced to analyze sperm quality in breeding centers. This review focuses on a sperm macromolecule, called proAKAP4 that have been successfully introduced as a pertinent indicator of sperm quality and fertility in mammals. Albeit absence or weak expression of AKAP4 have been described over the years as being related to sperm dysfunctions with motility impairments, proAKAP4 was under investigated up to recently due to the lack of reliable tools. Sandwich ELISA kits known as $4 \mathrm{MID} \circledast$ kits have recently reached the artificial insemination markets and brought new highlights about the proAKAP4 master role in reproduction. Structurally, proAKAP4 must be processed to release the mature AKAP4, that is essential to coordinate major transduction signals regulating sperm motility and fertility. ProAKAP4 amount as quantified in ejaculated spermatozoa reflect the ability of spermatozoa to keep active and functional up to the site of fertilization. Any modification of proAKAP4 expression during spermatogenesis or modification of its metabolism will have consequence on sperm motility, sperm capacitation and fertility. Consolidated data from field studies have shown correlation between proAKAP4 expression with fertility and prolificity. We will review here literature data on proAKAP4 involvement in spermatozoa functions and results in animal fertility. The translation of fundamental discoveries around proAKAP4 sperm protein marker to a functional tool such as $4 \mathrm{MID} \circledast$ kits will be beneficial in breeding industries and veterinarian practices.
\end{abstract}

Keywords: proAKAP4; 4MID®; Marker; Fertility; Prolificity; Quality; Innovation; Litter size

Abbrevations: AKAP4: A-Kinase Anchor Protein 4; PKA: Protein Kinase A; CASA: Computer Assisted Semen Analysis; VDAC2: Voltage Dependent Anion Channel 2; UQCRC2: Ubiquinol-Cytochrome-c Reductase Complex Core Protein 2

\section{Introduction}

From years now, investigations have been made to determine the fertilizing ability of ejaculated spermatozoa. No need to say that improving the classical methods to evaluate semen and predict fertility can result in significant economic savings for breeding industries and local breeders. Indeed, although artificial insemination is a very successful biotechnology, the breeding industry and breeders are facing major challenges associated with both male and female infertility. Progress advances issued from the fundamental researches around the male gamete have recently introduce biotechnology tools into livestock production. With proteins as actors of mobility and fertilization, being all produced before ejaculation of the spermatozoa, research studies were conducted to identify protein markers of sperm quality, fertility and/or prolificity. As proAKAP4 is a key protein in sperm physiology, the 4MID® technology (SPQI, Lille, France) that quantifies
proAKAP4 within spermatozoa have found field applications in animal breeding.

In this review, we will first discuss the sperm quality methods used in research institute and in breeding centers before focusing on proAKAP4, the sperm protein marker through the newly $4 \mathrm{MID} \AA$ approach designed for sperm quality and fertility assessment.

\section{Assessment of Sperm Quality: Still a Struggle}

\section{Main methods to assess sperm quality and their limits}

Sperm quality are classically based on the so-called sperm parameters (Table 1). The main sperm parameters include sperm concentration, morphology, and motility before and after thawing and they are routinely assessed manually using a light microscope 
and a spectrophotometer. Since manual analysis is markedly slow and prone to within and between technician errors due to subjectivity, computer-assisted semen analysis (CASA) have become the most popular method over years to produce sperm doses or frozen straws for artificial insemination [1-3]. This morphological way of exploring semen quality may appear subjective from a naïve observer, where sample sizes are small (100 to 1000 sper- matozoa counted and observed) from one ejaculate that comptabilized billions. Flow cytometry has been suggested to evaluate semen quality as it permits to study wider sperm populations. Flow cytometry as computer assisted sperm analyses allows parallel functional analysis such as sperm chromatin structure assay, measurements of oxidation levels and integrity of membranes including acrosomal, mitochondrial status and viable [4].

Table 1: Comparison of sperm quality assessment methods.

\begin{tabular}{|c|c|c|c|c|}
\hline $\begin{array}{l}\text { Sperm Assement } \\
\text { Method }\end{array}$ & $\begin{array}{l}\text { Number of cell } \\
\text { analyzed }\end{array}$ & Sperm Parameter & Test Duration & Number of samples \\
\hline Macroscopic Analysis & 1 ejaculate & $\begin{array}{c}\text { Color, Volume } \\
\text { Viscosity, Morphology }\end{array}$ & Less than $5 \mathrm{~min}$ & 1 sample at the time \\
\hline Spectrophotometry & 10 to 100 billions & Concentration & Less than 5 min & 1 sample at the time \\
\hline CASA & 100 to 1000 cells & $\begin{array}{c}\text { Motility, Concentration } \\
\text { Morphology } \\
\text { Vitality }\end{array}$ & $10 \mathrm{~min}$ & 1 sample at the time \\
\hline Flow Cytometry & $\begin{array}{c}10000 \text { à } \\
20000 \text { cells }\end{array}$ & $\begin{array}{l}\text { Concentration, Morphology } \\
\text { Subpopulation, Debris }\end{array}$ & $\begin{array}{l}20 \mathrm{~min} \\
\text { Up to hours } \\
\text { With dye staining }\end{array}$ & 1 sample at the time \\
\hline Microscopy & 10 to 100 cells & $\begin{array}{l}\text { Massale motility } \\
\text { Subpopulations } \\
\text { Morphology }\end{array}$ & $\begin{array}{l}\text { Less than } 5 \text { min } \\
\text { Up to hours with dye/anti- } \\
\text { bodies staining }\end{array}$ & 1 sample at the time \\
\hline 4MID ${ }^{\circledR}$ Kit & 100000 cells & $\begin{array}{l}\text { ProAKAP4 is correlated with: } \\
\text { Motility, Concentration Morpholo- } \\
\text { gy (sperm abnormalities) Fertility } \\
\text { Prolificity }\end{array}$ & Less than $2 \mathrm{~h}$ & 87 samples simulatenously \\
\hline
\end{tabular}

However, this method is expensive, time-consuming and difficult to implement in the routine of semen production centers. In vitro tests have been developed to evaluate sperm functions, such as analyses of sperm morphology, the cervical mucus penetration assay and sperm-zona pellucida interaction test [2]. Metabolic assessment of sperm features or the analysis of reactive oxygen species that have been proved to negatively impact sperm survival and fertility through their actions on lipid membrane structures, bringing great hope at the fundamental point of view [5]. These methods are interesting to understand, and open new pathways implicated in sperm physiology. Even if they are so-called fertility assays, they assess the defaults that affect the functionality of spermatozoa (such capacitation, acrosome reaction, sperm-oocyte interaction) but they do not yet predict fertility $[2,6]$. Up to day, they are mainly restrained to experimental approaches of sperm quality, and not adapted yet to the daily-routine sperm processing industries.

Although semen with high concentrations and high percentages of total and progressive motile spermatozoa are selected, they remain unsatisfactory to predict the fertility rate [1-2,7]. Objective criteria and their specific impacts on fertility are needed for a better understanding of the causes of poor-quality semen. Then, there still exists significant fertility differences among livestock animals, and low/hypofertile males are unknowingly used to inseminate a multitude of females until the reproductive status of the male can be established. Furthermore, in intensive breeding sectors, the identification of animals with the best semen quality is imperative to reduce the costs of raising animals. Both breeders and breeding companies are aware of these problems around sperm quality assessment and, without losing their genetic objectives, are constantly seeking out new tools and technologies to predict male fertility more accurately in order to offer high fertility sperm. Investigations of proteomic markers within the spermatozoa should clearly help to design functional tests that can reliably predict the highest fertility animals or their semen prior to breeding.

\section{Quantifying a Protein Actor as a Functional Test of Sperm Quality and Fertility}

Sperm macromolecules are primary indicators of sperm physiology and by understanding the intricate cell biology of male gamete, should help to predict sperm quality, functionality and fertility. Sperm proteins play important roles in support of motility which includes providing energy, structure, signaling, binding to the oocyte, acrosome reaction and nuclear functions [2,7]. From years now, investigators have struggled to identify semen quality parameters that will predict the fertility outcomes. Sperm triosephosphate isomerase and seminal plasma glutathione peroxidase were shown to be present in higher amounts in low-quality semen and were negatively associated with sperm motility in boars [8]. Sperm from high fertility bulls exhibited higher levels of proteins Enolase 1, Apoptosis-stimulating of p53 protein 2, and Phospholipid hydroperoxide glutathione peroxide, whereas sperm from 
low fertility bulls had elevated levels of voltage dependent anion channel 2 (VDAC2) and ubiquinol-cytochrome-c reductase complex core protein 2 (UQCRC2) [9]. More recently, high concentrations of seminal plasma PSP-I and cathepsin B in boar seminal plasma were shown to be associated with reduced total and progressive sperm motility [10].

The identification of these protein markers makes recently possible the development of new biotechnological and proteomics tools and methods for evaluating ejaculate's quality with fertility potential. Indeed, proAKAP4 is one of fertility associated protein markers that have been identified more than 30 years from now and have been today developed as a robust tool as we will described below. With the 4 MID ${ }^{\circ}$ kits, that quantify the proAKAP4 is fresh as in frozen semen, breeders have today a valuable tool to evaluate semen quality and predict fertility in bull and swine $[11,12]$. This newly approach to evaluate semen quality and fertility is based on a protein marker detected through a sandwich ELISA kit format that analyze up to 87 semen simultaneously (Table 1). With highly specific antibodies specific of the sperm marker, this functional test show now no interferences described with seminal proteins, bloods or other chemical elements in extenders or cryopreservation. Besides of being simple and cost effective, the $4 \mathrm{MID} \AA$ kits and the information provided by such a test is a reliable and easy to interpret, providing a follow up of sperm quality inside and between breeding centers, and during the animal career. The 4 MID $\AA$ kits represent today a good example of how biotechnology tools can get into routine as innovative and pertinent tools for breeders.

\section{Proakap4 Concentrations as an Indicator of Sperm} Quality and Fertility

\section{What is proAKAP4?}

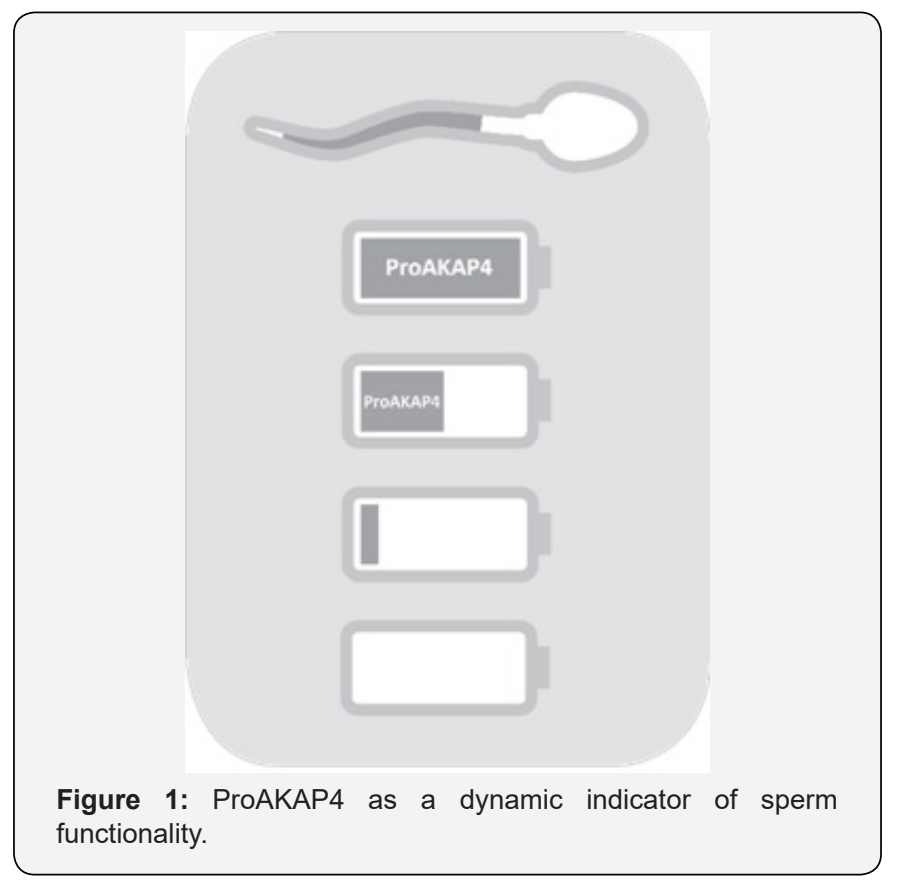

ProAKAP4 is namely the precursor of the AKAP4 protein with an extra sequence of the protein called the prodomain resulting from the full gene translation [13-15]. The proAKAP4 (Akap4) gene is located at Xp 11.22 locus of the short arm of the human $\mathrm{X}$ chromosome [16]. The proAKAP4 is a highly conserved molecule in between species from reptiles such as lizard and crocodile through all mammals and sharing more than $70 \%$ of homology [17-19]. The AKAP4 is largely known as the sperm specific member of the large family of the A-kinase anchor family of protein $[15,20]$. AKAP family members are all sharing the property to bind to the regulatory subunit of protein kinase A (PKA) and to confine the active holoenzyme to discrete cellular localizations [15,20$22]$. Both the precursor and active protein are found in spermatozoa and the precursor proAKAP4 will exist then in spermatozoa as a storage form of the AKAP4 active molecule (Figure 1).

As ejaculated spermatozoa are transcriptionally inactive, the proAKAP4 is fully synthetized in testis and before ejaculation. Interestingly the Akap4 gene is only expressed in the postmeiotic phase of spermatogenesis at the round tide stage [13-23]. In mice, AKAP4 is detected in the cytoplasm and flagellum from step 14 condensing spermatids (stages II-III) [13]. Both the precursor and the mature form of AKAP4 are strictly localized to the principal piece of the flagellum and not in other spermatozoa compartments [23]. Moreover, proAKAP4 and AKAP4 are tightly anchored to the fibrous sheath and are present in the longitudinal columns and ribs of the sperm tail [14]. Both forms of AKAP4 account for nearly half the protein in mouse sperm fibrous sheaths [24]. This specific and restricted localization is necessary to AKAP4 functions. The proAKAP4 precursor has to be processed to release the AKAP4 functional protein that in turn is integrated in the fibrous sheath of the principal piece of the flagellum together with other components of the fibrous sheath such as the fibrous sheath interacting protein 1 and 2. The mature AKAP4 recruits then protein kinase A holoenzyme (PKA) to the fibrous sheath and facilitates local phosphorylation of substrates to regulate flagellar function and spermatozoa motility $[20,22,25]$.

Today more than 160 references citing AKAP4 in reproductive field can be found in database such as PubMED. In the literature, AKAP4 is also referred as AKAP82, PRKA4 (Protein Kinase an Anchoring Protein 4), CT99 (Cancer/Testis Antigen 99), HI, p82, and also FSC1 (Fibrous Sheath Component 1) when AKAP4 was initially identified. Altogether, they highlight the master roles of proAKAP4 and AKAP4 in spermatozoa flagellar structure and functions.

\section{ProAKAP4 and spermatogenesis quality}

The spermatogenesis is a series of events during which spermatogonial stem cells undergo divisions to form haploid round spermatids and then transformation into elongated mature sperm having a head and tail up to the mature spermatozoa that are ejaculated. ProAKAP4 is expressed only from the spermatid levels and not found at earliest stages $[13,26]$. The full stock of proAKAP4 in each individual spermatozoon is made before ejaculation, as spermatozoa are transcriptionally inactive. In contrast, AKAP4 amount 
will be modulated according the initial stock of proAKAP4 and its metabolic status. Thus, any defective event during spermatogenesis will impact the expression of proAKAP4 precursor $[27,28]$. Even fertile animals may produce ejaculates with poor fertilizing capacities depending on their age or environment (treatments, heat, stress, endocrine disruptors, etc.). For instance, exposures of endocrine disruptors have been shown to modulate the expression of proAKAP4 and AKAP4 in rats $[28,29]$. Therapeutic treatments such as antibiotics or vaccines could also have consequences on metabolism, on spermatogenesis, and the proAKAP4 levels could also be modulated. Measuring proAKAP4 concentrations when animals are under therapeutic treatments may be of interest for breeders to detect when semen quality is restored after treatment end.

\section{ProAKAP4 and Motility}

The sperm motility plays a central and major role in male fertility. Sperm motility is driven by the flagellum of spermatozoa which motion produces the motility though male and female genital tracts. Sperm motility can be split into two different types of motility, progressive motility and hypermotility which are distinguished by two mode of flagella beating. With progressive motility symmetrical waves are propagating along the flagellum leading to a linear propulsion [30]. Hypermotility as the result of hyperactivation is associated with asymmetrical waves down the flagellum with higher amplitude and associated with circular trajectories [30]. These types of motions are achieved via proteins that are energy related enzymes, both structural, and signaling actors. In the literature, there are several important sperm proteins necessary for sperm motility that have been identified. For instance, the Sperm Outer dense fiber protein 2 (ODF2) has been shown to play critical roles in sperm motility in the mouse [31]. In the complex molecular machinery that regulates sperm motility, AKAP4 has been shown to be an essential structural protein of the flagellum that regulate cyclic AMP, calcium-dependent PKA and PKC signaling $[22,25]$. There are many reports of AKAP4 being essential to coordinate the signal transduction of PKA to motor proteins such as dyneins and thus promote the sliding of microtubule doublets of the axoneme [22,26]. Any modification of proAKAP4 expression or metabolism will have consequence on sperm motility and then on fertility. Around $10 \%$ of more than 400 knockout mouse models showing male fertility have spermatozoa with impaired motility and/or sperm flagellum structural abnormalities [7]. Absence or weak expression of proAKAP4 and AKAP4 has been shown to be associated with a weak sperm motility and fibrous sheath dysplasia [32-34]. In AKAP4 knock out mice, spermatozoa are immotile and infertile [32]. In a cohort of 245 men consulting for men infertility, proAKAP4/AKAP4 were shown to be correlated with sperm motility $[35,36]$. More recently, proAKAP4 concentrations have been shown to correlate with total and progressive motility in post-thawed semen of stallion [37]. The amounts of proAKAP4 as quantified with the $4 \mathrm{MID} 囚$ kits may reflect the number of spermatozoa within ejaculate doses that keep motile up to the oocyte and fertilize.

\section{ProAKAP4 and Capacitation}

Capacitation is a cascade of molecular events leading to the acrosome reaction and hypermotility which occur in the sperm during ascending of the female reproductive tract [38]. The hyperactivation observed during capacitation included an upsurge of intracellular calcium and abundant tyrosine phosphorylation of flagellar proteins which are also involved in complex signaling cascade of events between cAMP/PKA and tyrosine kinase/phosphatase $[39,40]$. Both proAKAP4 and AKAP4 are flagellar substrates of phosphorylation by serine/threonine- and tyrosine-kinases in a capacitation-dependent manner in the spermatozoa [41-43]. Recently AKAP4 was identified in capacitated crocodile spermatozoa thus showing that this phenomenon of physiological capacitation is also occurring in spermatozoa of old Australian Salt Crocodiles [19] and this mechanism is then well-preserved in all animal species. Indeed, both proAKAP4 and AKAP4 are largely described to become heavily tyrosine and serine phosphorylated during capacitation and then appears as valuable marker for the capacitation status of spermatozoa in all mammals including bulls [41-47].

\section{ProAKAP4, Fertility and Prolificity}

ProAKAP4 expression has been associated with high phenotype fertility and appears today as a pertinent and innovative approach to assess fertility. Proteomics is clearly powerful approach to determine changes of protein expression or protein post-translation modifications between different conditions such as sperm parameters or sperm from animals with different status of fertility. Sperm from high fertility bulls were shown to have a higher expression of proAKAP4 than bulls with low fertile sperms [48]. ProAKAP4 expression was lowered in men with non-fertilizing sperm although sperm parameters were normal [49]. Processing of proAKAP4 allow AKAP4 to bind to other molecules such as AKAP3 and enolase 1, that are both reported to as fertility associated proteins. For instance, Enolase 1 (ENO1) have also been identified in sperm from high fertility bulls $[9,50]$. ProAKAP4 and AKAP4 expression has been associated with a better fertility of sperm in mammals [47-49,51,52]. ProAKAP4 as a sperm protein marker associated with high fertility potential should find applications for breeding activities especially if not linked to sophisticated and expensive techniques to be set up in lab quality control. Clearly, the fertilizing ability of ejaculated spermatozoa that can nowadays being evaluate though the $4 \mathrm{MID} \AA$ kit, that quantify expressing levels of proAKAP4.

Furthermore, recent data have shown that high proAKAP4 sperm concentration is an indicator of prolificity. Prolificity is matter of concern in boar breeding centers. Once more proteomics is a valuable method to address the question of whether the litter size resulting from artificial insemination could be underpinned by qualitative or quantitative modifications of the sperm proteome. Several protein markers related to prolificity have been identified after induction of capacitation in vitro [53]. However, this type of research approach is not fitting to the semen production breeding centers. In contrast, the methodology under 4MID® kits, mean- 
ing ELISA approaches, only request a plate reader equipment. The concentrations of proAKAP4 using the Pig 4 MID $®$ kit as measured in semen of 13 boars with similar sperm parameters, exhibited striking variations from a boar to another stressing out the interest to have a functional sperm parameter $[11,12]$. When the same semen doses of those followed animals were used to inseminate 210 sows, an increase of both fertility index and prolificity were observed in the groups of swine gathered according a threshold concentration of $45 \mathrm{ng}$ of proAKAP4 /10 millions of spermatozoa (unpublished data).

Processed dose semen presenting a proAKAP4 concentration above $45 \mathrm{ng} / 10$ million spermatozoa exhibited a clear increase fertility index (Table 2). Moreover, an average of 2.05 piglets was obtained with these doses with high proAKAP4 concentrations (Table 3). ProAKAP4 concentrations are then pertinent to predict fertility and litter size. Consequently, the use of the $4 \mathrm{MID} 囚$ kit could improve rentability in artificial insemination centers.

Table 2: ProAKAP4 and fertility in boars

\begin{tabular}{|c|c|c|c|c|}
\hline Sows & Total Births & $\begin{array}{c}\text { Dead at } \\
\text { birth }\end{array}$ & $\begin{array}{c}\text { Pig 4MID } \\
\text { (ng / ProAKAP4 } \\
\text { matozoa) }\end{array}$ & $\begin{array}{c}\text { Fertility } \\
\text { Index }\end{array}$ \\
\hline 71 & 882 & $7.8 \%$ & $<42$ & 1137 \\
\hline 68 & 1011 & $8.8 \%$ & $>45$ & 1311 \\
\hline
\end{tabular}

Table 3: ProAKAP4 and prolificity in boars.

\begin{tabular}{|c|c|}
\hline $\begin{array}{c}\text { Pig } 4 \text { MID }^{\circledR} \text { ProAKAP4 (ng /10millions spermato- } \\
\text { zoa) }\end{array}$ & Prolificity \\
\hline$<42$ & $12.57 \pm 1.19$ \\
\hline$>45$ & $14.62 \pm 1.02$ \\
\hline & $\pm \mathbf{2 . 0 5}$ piglets \\
\hline
\end{tabular}

\section{Concluding Remarks}

Investigations of molecular actors through proteomic methods have help to underline mechanisms of male fertility and have generate new methods to improve semen quality and pre-dict fertility. The proAKAP4 precursor is a key protein that is playing crucial roles in sperm physiology. The fertilizing ability of ejaculated spermatozoa that can nowadays being evaluate through the $4 \mathrm{MID} \AA$ kits, that quantify expression levels of proAKAP4 in ejaculate and/or doses. Measuring proAKAP4 level of expressions should generate pertinent information to guide the prognosis of male fertility and prolificity in breeding activities. The 4MID® kits represent a good example of how biotechnology and proteomics tools can get into routine as an innovative tool for breeders. Such examples could lead to the development of other innovative markers to improve sperm quality assessment in competitive breeding industries, animal reproduction clinics and veterinarian practices and being a breakthrough in the field of artificial insemination.

\section{Acknowledgements}

The authors are grateful to Dr. Mickael Perrais for his scientific advices and sharing all his research network. Research investigations and analysis were performed under grants from
BPI and Re-gion Hauts de France for MD and NS.

\section{Conflict of Interest}

NS and MD are co-founders of SPQI, a spin-off company (Lille, France).

\section{References}

1. Farrell PB, Presicce GA, Brockett CC, Foote RH (1998) Quantification of bull sperm characteristics measured by computer-assisted sperm analysis (CASA) and the relationship to fertility. Theriogenology 49: 871-879.

2. Aitken RJ (2006) Sperm function tests and fertility. Int J Andrology 29(1): 69-75.

3. Amann RP, Wabesrki D (2014) Computer-assisted sperm analysis (CASA): capabilities and potential developments. Theriogenology 81(1): 5-17.

4. Robles V, Martínez Pastor F (2013) Flow cytometric methods for sperm assessment. Methods Mol Biol 927: 175-186.

5. Jung M, Rüdiger K, Schulze M (2015) In Vitro Measures for Assessing Boar Semen Fertility. Reprod Domest Anim 50 (2): 20-24.

6. Braundmeier AG, Miller DJ (2001) The search is on finding accurate molecular markers of male fertility. J Dairy Science 84(9): 1915-1925.

7. Matzuk MM, Lamb DJ (2008) The biology of infertility: research advances and clinical challenges. Nat Med 14: 1197-213.

8. Vilagran I, Castillo-Martin M, Prieto-Martinez N, Bonet S, Yeste M (2016) Triosephosphate isomerase (TPI) and epididymal secretory glutathione peroxidase (GPX5) are markers for boar sperm quality. Anim Reprod Sci.165: 22-30.

9. Park YJ, Kwon WS, Oh SA, Pang MG (2012) Fertility-related proteomic profiling bull spermatozoa separated by percoll. J Proteome Res 11(8): 4162-4168.

10. De Lazari FL, Sontag ER, Schneider A, Moura AAA, Vasconcelos FR, et al. (2018) Seminal plasma proteins and their relationship with sperm motility and morphology in boars. Andrologia 27: e13222.

11. Delehedde M, Bloomaert D, Jouy N, Scabello J, Miersman H et al. (2018) Concentration of proAKAP4 as a pertinent read-out of sperm quality in mammals. Animal Rep Science 194: 24.

12. Sergeant N, Jumeau F, Eddarkaoui S, Sigala J, Dossou GF, et al. (2016) Investigating proteomic methods and tools to assess sperm quality. Animal Reproduction Science 169: 99.

13. Brown PR, Miki K, Harper D, Eddy EM (2003) A-kinase anchoring protein 4 Binding Proteins in the Fibrous Sheath. Biol Rep 68: 22412248.

14. Johnson LR, Foster JA, Haig-Ladewig L, VanScoy H, Rubin CS, et al. (1997) Assembly of AKAP82, a protein kinase A anchor protein, into the fibrous sheath of mouse sperm. Dev Biol 192: 340-350.

15. Luconi M, Cantini G, Baldi E, Forti G (2011) Role of A-kinase anchoring proteins (AKAPs) in reproduction. Frontiers in Bioscience 16: 13151330.

16. Turner R, Johnson L, Haig-Ladewig L, Gerton G, Moss S (1998) An $\mathrm{X}$-linked gene encodes a major human sperm fibrous sheath protein, hAKAP82. J Biol Chem 273: 32135-32141.

17. Moss S, Turner R, Burkert K, Butt H, Gerton G (1999) Conservation and function of a bovine sperm A-kinase anchor protein homologous to mouse AKAP82. Biology of Reproduction 61: 335-342.

18. Hu Y, Yu H, Pask A, O’Brien D, Shaw G, Renfree M (2009) A-kinase anchoring protein 4 has a conserved role in mammalian spermatogenesis. Reproduction 137: 645-653. 
19. Nixon B, Johnston SD, Skerrett-Byrne DA, Anderson AL, Stanger SJ, et al. (2018) Proteomic profiling of crocodile spermatozoa refutes the tenet that post-testicular maturation is restricted to mammals. Mol Cell Proteomics 15: S59-S76.

20. Luconi M, Carloni V, Marra F, Ferruzzi P, Forti G, et al. (2004) Increased phosphorylation of AKAP by inhibition of phosphatidylinositol 3-kinase enhances human sperm motility through tail recruitment of protein kinase A. J Cell Science 117: 1235-1247.

21. Miki K, Eddy EM (1999) Single amino acids determine specificity of binding of protein kinase A regulatory subunits by protein kinase A anchoring proteins. J Biol Chem 274: 29057-29062.

22. Vijayaraghavan S, Goueli SA, Davery MP, Carr DW (1997) Protein kinase A-anchoring inhibitor peptides arrest mammalian sperm motility. J Biol Chem 272: 4747-4752.

23. Carrera A, Gerton GL, Moss SB (1994) The major fibrous sheath polypeptide of mouse sperm: structural and functional similarities to the A kinase anchoring proteins. Dev Biol 165: 272-284.

24. Eddy EM, Toshimori K, O’Brien DA (2003) Fibrous sheath of mammalian spermatozoa. Microsc Res Tech 61: 103-115.

25. Huang Z, Somanath P, Chakrabarti R, Eddy EM, Vijayaraghavan S (2005) Changes in intracellular distribution and activity of protein phosphatase PP1g2 and its regulating proteins in spermatozoa lacking AKAP4. Biol Reproduction 72: 384-392.

26. Nipper RW, Chennothukuzhi V, Tutuncu L, Williams CJ, Gerton GL, et al. (2005) Differential RNA expression and polyribosome loading of alternative transcripts of the Akap4 gene in murine spermatids. Mol Reprod Dev 70(4): 397-405.

27. Delbes G, Yanagiya A, Sonenberg N, Robaire B (2012) PABP interacting protein 2A (PAIP2A) regulates specific key proteins during spermiogenesis in the mouse. Biol Reprod 86(3): 95.

28. Baker MA, Hetherington L, Weinberg A, Naumovski N, Velkov T, et al. (2012) Analysis of phosphopeptide changes as spermatozoa acquire functional competence in the epididymis demonstrates changes in the post-translational modification of Izumo1. J Proteome Res 11(11) 5252-5264.

29. Auger J, Eustache F, Maceiras P, Broussard C, Chafey P, et al. (2010) Modified expression of several sperm proteins after chronic exposure to the antiandrogenic compound vinclozolin. Toxicol Sci 117(2): 475484

30. Curtis MP, Kirkman-Brown JC, Connolly TJ, Gaffney EA (2012) Modelling a tethered mammalian sperm cell undergoing hyperactivation. J Theor Biol 309: 1-10.

31. Tarnasky H, Cheng M, Ou Y, Thundathil JC, Oko R, et al. (2010) Gene trap mutation of murine outer dense fiber protein-2 gene can result in sperm tail abnormalities in mice with high percentage chimaerism. BMC Dev Biol 10: 67.

32. Miki K, Goulding EH, Fulcher KD, Eddy E, Willis WD, et al. (2002) Targeted disruption of the Akap4 gene causes defects in sperm flagellum and motility. Developmental Biology 248: 331-342.

33. Moretti E, Scapigliati G, Pascarelli NA, Baccetti B, Collodel G (2007) Localization of AKAP4 and tubulin proteins in sperm with reduced motility. Asian Journal of Andrology 9: 641-649.

34. Baccetti B, Collodel G, Estenoz M, Manca D, Moretti E, et al. (2005) Gene deletions in an infertile man with sperm fibrous sheath dysplasia. Human Rep 20: 2790-2794

35. Jumeau F, Sigala J, Fernandez-Gomez FJ, Eddarkaoui S, Duban-Deweer S, et al. (2018) Gel electrophoresis of human sperm: a simple method for evaluating sperm protein quality. Basic Clin Androl 28: 10.

36. Jumeau F, Sigala J, Dossou-Gbete F, Frimat K, Barbotin AL, et al. (2018) A-kinase anchor protein 4 precursors (pro-AKAP4) in human spermatozoa. Andrology 6(6): 854-859.
37. Blommaert D, Sergeant N, Delehedde M, Franck T, Lejeune JP, et al. (2018) Significant Correlation Between the proAKAP4 Concentration and the Total and Progressive Motility in Stallion Sperm After Thawing. J Equine Vet Science 66: 43.

38. Suarez SS, Pacey AA (2006) Sperm transport in the female reproductive tract. Hum Reprod Update 12: 23-37.

39. Baldi E, Casano R, Falsetti C, Krausz C, Maggi M, et al. (1991) Intracellular calcium accumulation and responsiveness to progesterone in capacitating human spermatozoa. J Androl 12: 323-330.

40. Marquez B, Suarez SS (2004) Different signaling pathways in bovine sperm regulate capacitation and hyperactivation. Biol Reprod 70(6): 1626-1633.

41. Ficarro S, Chertihin O, Westbrook VA, White F, Jayes F, et al. (2003) Phosphoproteome Analysis of Capacitated Human Sperm: Evidence of tyrosine phosphorylation of a kinase-anchoring protein 3 and valosincontaining protein/p97 during capacitation. J Biol Chem 278: 1157911589.

42. Baker M, Smith N, Hetherington L, Taubman Kristy, Graham M, et al. (2010) Label-free quantitation of phosphopeptide changes during rat sperm capacitation. Journal of Proteome Research 9: 718-729.

43. Jagan Mojanarao G, Atreja SK (2001) Identification of capacitation associated tyrosine phosphoproteins in buffalo and cattle spermatozoa. Animal Reproduction Science 123: 40-47.

44. Visconti P, Johnson L, Oyaski M, Fornés M, Gerton G, et al. (1997) Regulation, localization, and anchoring of protein kinase-A subunits during mouse sperm capacitation. Developmental Biology 192: 351363.

45. Turner RM, Eriksson RL, Gerton GL, Moss SB (1999) Relationship between sperm motility and the processing and tyrosine phosphorylation of two human sperm fibrous sheath proteins, prohAKAP82 and hAKAP82. Mol Hum Reprod 5: 816-824.

46. Platt M, Salicioni A, Hunt D,Visconti P (2009) Use of differential isotopic labeling and mass spectrometry to analyze capacitation-associated changes in the phosphorylation status of mouse sperm proteins. J. Proteome Res. 8: 1431-1440.

47. Redgrove K, Nixon B, Baker M, Hetherington L, Baker G, et al. (2012) The molecular chaperone HSPA2 plays a key role in regulating the expression of sperm surface receptors that mediate sperm-egg recognition. Plosone 7: 1-16.

48. Peddinti D, Nanduri B, Kaya A, Feugang JM, Burgess SC, et al. (2008) Comprehensive proteomic analysis of bovine spermatozoa of varying fertility rates and identification of biomarkers associated with fertility. BMC Systems Biology 2: 19.

49. Frapsauce C, Pionneau C, Bouley J, Delarouziere V, Berthaut, et al. (2014) Proteomic identification of target proteins in normal but non fertilizing sperm. Fertility Sterility 102: 372-381.

50. Soggiu A, Piras C, Hussein HA, De Canio M, Gaviraghi A et al. (2013) Unravelling the bull fertility proteome. Mol Biosyst. 6: 1188-1195.

51. Légaré C, Akintayo A, Blondin P, Calvo E, Sullivan R (2017) Impact of male fertility status on the transcriptome of the bovine epididymis. Mol. Human Rep 1: 1-15.

52. Singh R, Junghare V, Hazra S, Singh U, Sengar GS, et al. (2019) Database on spermatozoa transcriptogram of catagorised Frieswal crossbred (Holstein Friesian X Sahiwal) bulls. Theriogenology 129:130-145.

53. Kwon WS, Oh SA, Kim YJ, Rahman MS, Park YJ, et al. (2015) Proteomic approaches for profiling negative fertility markers in inferior boar spermatozoa. Sci Rep 8(5): 13821. 
- Quality Editorial service

- Swift Peer Review

- Reprints availability

- E-prints Service

- Manuscript Podcast for convenient understanding

- Global attainment for your research

- Manuscript accessibility in different formats ( Pdf, E-pub, Full Text, Audio)

- Unceasing customer service

Track the below URL for one-step submission https://juniperpublishers.com/online-submission.php 